\title{
ESTRUTURA ORGANIZACIONAL E PROCESSO DECISÓRIO
} LEGISLATIVO

\section{ORGANIZATIONAL STRUCTURE AND LEGISLATIVE DECISION MAKING PROCESS}

\author{
Ricardo de João Braga \\ Roberto Campos da Rocha Miranda*
}

Resumo: O artigo tem como objetivo principal realizar uma abordagem interdisciplinar sobre os processos decisórios e a estrutura organizacional da Câmara dos Deputados, sob uma perspectiva ao mesmo tempo crítica da literatura existente e exploratória em relação às possibilidades abertas pela interdisciplinaridade. Fruto da experiência dos autores na condução da disciplina Estrutura Organizacional e Processo Decisório Legislativo, do Mestrado Profissional em Poder Legislativo da Câmara dos Deputados, ampara-se na literatura sobre estrutura organizacional, processo decisório e comportamento legislativo para avaliar o funcionamento do Legislativo. O trabalho insere o Poder Legislativo no contexto do estudo das organizações e aponta possibilidades e limites para as visões informacional e organizacional desse Poder, tidas ainda como um campo de escassas produções acadêmico-científicas. Os resultados do estudo indicam que é possível analisar o Legislativo sob a ótica de teorias das Ciências da Informação e da Administração, identificando estruturas e processos decisórios próprios da casa legislativa e apontando aspectos comuns entre esta e outras organizações. Permite também avaliar que a contribuição dos estudos legislativos para a compreensão dos processos decisórios na Câmara dos Deputados avançam mais sobre suas macrocaracterísticas, como a organização colegiada-centralizada, do que sobre a natureza dos processos decisórios e comportamentos individuais dos parlamentares

Palavras-chaves: Poder Legislativo; Processo Decisório Legislativo; Tomada de Decisão; Estrutura Organizacional.

Abstract: This article intends to apply an interdisciplinary approach to the Chamber of
Deputies' decision making process and organizational structure. It criticizes the actual literature
and explores the possibilities unfold by the interdisciplinary approach. A course on
Organizational Structure and Parliamentary Decision Making Process taught by the authors is
* Ricardo de João Braga, economista, mestre e doutor em Ciência Política, professor do curso de Mestrado em
Poder Legislativo e de cursos de especialização do Programa de Pós-Graduação do Cefor da Câmara dos
Deputados. (ricardo.braga@ @amara.leg.br) Roberto Campos da Rocha Miranda, administrador postal, especialista
em Gestão de Pessoas no Setor público, mestre e doutor em Ciências da Informação, professor do Instituto de
Educação Superior de Brasília e professor do curso de Mestrado em Poder Legislativo e de cursos de
especialização do Programa de Pós-Graduação do Cefor da Câmara dos Deputados. (roberto.rocha@camara.leg.br) 
the main input for the arguments and analysis, and the theoretical foundations for them are the academic disciplines related to organizational structure, decision making process and legislative behavior. There is a lack of studies that conceive the Legislative Branch as an organization, so this article applies the organizational approach and points some potentialities and limits of its use, specifically to the informational and organizational theoretical perspectives. Findings demonstrate that it is useful to apply theories of Information Science and Public Administration to the Parliamentary analysis, which are able to identify structures and decision making process common to Legislative Branch and other organizations. Legislative studies focused on the Brazilian Chamber of Deputies are useful to capture major features of the institution, like the centralized college of relevant decision makers, but they are humble to understand the nature of the decision making process and the individual behavior of the decision makers.

Keywords: Legislative Branch; Legislative Decision; Making Process; Organizational Structure.

\section{Introdução}

O Poder Legislativo como fenômeno e objeto de pesquisa é visto no Mestrado Profissional em Poder Legislativo da Câmara dos Deputados como algo complexo e passível de análise sob diversos enfoques. Uma dessas propostas possíveis, consubstanciada em cadeira específica do curso, procurou reunir contribuições de três disciplinas tradicionais no desafio que é a construção de um saber interdisciplinar: Ciência Política, Administração e Ciência da Informação.

Comportamento e instituições legislativos, atualmente mesclados nos modelos neoinstitucionalistas, foram o aporte dado pela Ciência Política. A análise da estrutura organizacional e de seu impacto no processo de tomada de decisões é provido pelas Ciências da Administração, e o fluxo informacional e modelos de tomada de decisão são contribuições oriundas das Ciências da Informação. O arcabouço teórico desta pesquisa, portanto, baseia-se nesses três pilares.

A pretensão central deste artigo é, a partir da análise crítica do aporte dessas teorias e do diálogo estabelecido na dinâmica do curso, mostrar como a interdisciplinaridade pôde encontrar espaço e perspectivas de desenvolvimento. Longe de esgotar possibilidades ou apresentar posições definitivas, este artigo atém-se a construir um marco inicial lógico-teórico para esta específica interdisciplinaridade que se tentou construir e apontar alguns elementos importantes de análise dentro dessa perspectiva.

Assim o trabalho se estrutura apresentando a inquietação concreta com a qual se depara a Ciência Política, as teorias que buscam entender a tomada de decisão no parlamento, a visão teórico-exemplificativa do processo decisório aplicado ao parlamento, os modelos de tomada de 
decisão e sua apropriação no legislativo, elementos da estrutura organizacional e seus desdobramentos na Câmara dos Deputados e, finalmente, tipos de estrutura organizacional, na visão de Mintzberg (2012), e as correspondências com as estruturas de Casas Legislativas.

\section{O Ponto de Partida da Ciência Política: a caixa-preta informacional}

Um olhar sobre a realidade do Legislativo brasileiro permite afirmar que uma das atividades que mais consomem tempo e energia dos parlamentares é o levantamento e a análise de informações. Seu dia a dia no Congresso é marcado por inúmeras reuniões, audiências e contatos informais com outros parlamentares e deles com autoridades, grupos de pressão e cidadãos comuns. Elemento importante a destacar são as reuniões e encontros fechados, privativos de parlamentares, tais como quando se reúnem no Colégio de Líderes, em algumas situações específicas em comissões e principalmente no contato informal - se são reservadas, é porque informações que lá circulam têm valor e importância e não podem alcançar o público externo. Ainda, não se pode negligenciar o contato com jornalistas (para a troca de informações e não apenas para alimentar um canal de mão única) e o hábito da leitura de jornais, especialmente alguns colunistas selecionados que funcionam como termômetros de assuntos relevantes ou porta-vozes não oficiais deste ou daquele ator importante.

Quanto à organização, o Legislativo brasileiro conta com consultorias próprias especializadas em orçamento e diversas áreas temáticas. Tais consultorias não se ocupam de serviço de secretaria ou organização de atividades, mas sim de estudos e preparação de material para análise, discussão e votação. Há também as assessorias, de lideranças ou de gabinete, que têm como uma das funções principais selecionar informações sobre o que está sendo discutido de interesse dos parlamentares e as posições deste ou daquele ator. Ainda, as próprias comissões, pela especialização em áreas temáticas, são pontos focais para atração de informações e atores interessados nas políticas sob sua competência.

Outro elemento importante, que mostra o Legislativo como local e canal de discussão, é a própria exposição de análises e posições políticas. Em Plenário ou em encontros informais, os parlamentares têm a oportunidade de integrarem-se em um sistema maior de troca de informações sobre cenário político, movimentação de atores, novas ideias e propostas, algo que toca a sobrevivência política dos parlamentares. Na condição de grupo de atores que fazem parte de um sistema que se renova de tempos em tempos por meio de eleições - situação que exige o constante monitoramento e tomada de posição com esta ou aquela coalizão -, é valiosa a oportunidade de interagir com os outros atores, analisar situações e sondar possibilidades.

Vê-se assim que o Legislativo funciona como um meio de produção e disseminação de informações relevantes para o Parlamentar, seja por suas vias ordinárias de produção legislativa ou pelo simples fato de ser ponto de encontro de interessados e oportunidade de expressão de ideias. Quanto ao parlamentar como indivíduo, a utilização de recursos (financeiros, humanos, 
materiais e outros) para participar de processos informacionais denota a necessidade e a importância da questão para sua sobrevivência política.

Não obstante o quadro traçado, pode-se afirmar que os estudos contemporâneos de Ciência Política que tratam do Legislativo problematizam de forma insuficiente seu processo decisório. O que se constata na literatura é a apresentação de alguns poucos problemas tidos como centrais para a organização legislativa - especialmente quem controla a organização e como a formata para atender seus objetivos - e a modelagem de agentes relativamente simples e pouco envolvidos em coletar e analisar informações.

Como afirmam Polsby e Schikler (2002), mesmo nos EUA, em que os estudos legislativos são mais desenvolvidos, um olhar específico para dentro da organização, que buscasse uma compreensão mais extensa e sistemática do papel da estrutura e seus incentivos para os processos decisórios, ocorreu apenas a partir dos anos 1970, com o avanço do neoinstitucionalismo. Até então prevaleciam visões normativas sobre o papel do Legislativo (o institucionalismo antigo, baseado no modelo Westminster de partidos responsáveis) e a abordagem sociológica, que compreendia como variáveis determinantes e independentes para os resultados legislativos a estrutura de interesses e identidades construídas fora do Legislativo.

\section{Teorias de Tomada de Decisão e o Parlamento}

Diante da necessidade de avançar sobre a literatura que valoriza o Legislativo como organização ${ }^{1}$, passou-se à perspectiva dos estudos legislativos neoinstitucionalistas, os quais apresentam desenvolvimento tanto nos EUA quanto em outros países, incluído neles o Brasil.

O neoinstitucionalismo dos estudos legislativos foi erigido a partir dos anos 1970 nos EUA, baseado em perspectivas econômicas de racionalidade e otimização (MAYHEW, 1974). Ele se posiciona em relação a dois conjuntos teóricos relevantes. Dentro dos estudos legislativos, o neoinstitucionalismo vem posteriormente e como avanço em relação a perspectivas sociológicas e institucionalistas (POLSBY; SCHIKLER, 2002). Por outro lado, o neoinstitucionalismo dos estudos legislativos se diferencia de outras correntes próximas, como o Institucionalismo Histórico e o Sociológico (HALL; TAYLOR, 2003), diferença que o qualifica, segundo esses autores, como 'Institucionalismo da Escolha Racional'.

O neoinstitucionalismo dos estudos legislativos é uma perspectiva de análise focada sobretudo no funcionamento do Congresso a partir de seus próprios condicionantes internos, em especial suas regras de funcionamento, podendo-se compreendê-lo como a análise de um jogo: importam as regras de ação e de interação entre os jogadores; objetivos pessoais (preferências) são tidos como dados; e o conhecimento das regras do jogo e da ação dos outros participantes é um pressuposto.

\footnotetext{
${ }^{1}$ Sintomático dessa realidade é o próprio título da obra de Krehbiel (1992), importante autor dos estudos neoinstitucionalistas do Poder Legislativo: Information and Legislative Organization.
} 
O bordão que 'as regras importam' passou a ser um marco comum para as perspectivas teóricas surgidas no neoinstitucionalismo. A valorização analítica das instituições legislativas (suas regras de funcionamento) veio como resposta ao paradoxo das maiorias estáveis com que se defrontou a escolha racional. Se os pressupostos da teoria da escolha racional fossem acertados, a ação livre dos indivíduos iria acarretar a ausência de equilíbrio e de estabilidade nas decisões (MCKELVEY, 1976). Como a realidade era de estabilidade e equilíbrio, a solução foi encontrada nas instituições, que restringiam o comportamento dos parlamentares, e assim passaram a ser objeto analítico central.

As regras passam então a ter status de variável independente e relevante na produção dos resultados legislativos. Conforme apresenta a "equação de Plott" (HINICH; MUNGER, 1998, p. 17), os resultados (outcomes) de interações sociais dizem respeito à interação entre regras e preferências. Dizer que as regras importam é afirmar que estas influenciam os resultados legislativos de forma independente e significativa: se as regras mudam, os resultados podem ser alterados, mesmo se não alteradas as preferências dos participantes.

Para a disciplina Estrutura Organizacional e Processo Decisório Legislativo, o bordão 'que as regras importam' sustentou a discussão da relação entre estrutura organizacional e o processo decisório legislativo. Regras de interação entre agentes e estrutura de incentivos estariam em boa medida materializados na forma de organização dos legislativos: o que se quer, quanto se quer e quem pode fazer algo dentro do legislativo dependem em boa medida da definição de competências, órgãos e estruturas voltados a tais objetivos e da quantidade de recursos a eles alocados.

As três teorias neoinstitucionalistas trabalhadas no curso - distributivista (WEINGAST; MARSHALL, 1983), informacional (KREHBIEL, 1992) e partidária (KIEWIET, MCCUBBINS, 1991) - veem na estrutura organizacional do legislativo a materialização de incentivos e meio para atingimento da motivação dos parlamentares (a reeleição). Com vistas à discussão de processos decisórios no âmbito do Legislativo, devem ser apontados os seguintes elementos presentes nessas três versões teóricas:

- trabalham com uma motivação para a ação política (a reeleição);

- apontam um meio privilegiado para atingir a reeleição (a promoção individual do parlamentar ou coletiva, como legislatura ou partido);

- identificam uma razão para a estruturação e funcionamento dos órgãos da organização (ganhos de troca, promoção da sigla partidária, ganho informacional).

A reeleição como motivador político pode ter um caráter duplo, de achado empírico e de premissa analítica, mas para as teorias em análise o segundo deles é o preponderante. Outras explicações para a motivação dos agentes, como a realização de 'boas políticas públicas' ou influência na instituição (FENNO, 1973) podem até ser consideradas como realidades empíricas 
aceitáveis, mas são descartadas como premissas de análise. Utilizando a condensação cínica das 'teorias econômicas' da democracia (DOWNS, 2013; SCHUMPETER, 1984), pode-se dizer que os políticos apresentam propostas para ganhar eleições, e não ganham eleições para executar propostas - em outras palavras, a carreira política é um fim, e não um meio.

A motivação da reeleição faz com que os atores políticos sejam vistos como submetidos a uma lógica de ação instrumental, que valoriza a eficácia entre meios e fins. Como colocam Hall e Taylor (2003), o comportamento dos legisladores é visto numa perspectiva 'calculadora', que valoriza o cálculo estratégico e busca otimizar uma função de preferências (estas definidas exogenamente à análise institucional). Na forma de um exemplo concreto, é de importância marginal para essas teorias neoinstitucionalistas da escolha racional se o parlamentar é de direita ou esquerda, como se deu a construção de suas ideias e identidade. O que importa é que, definidos seus objetivos (de forma exógena à teoria), ele passa a responder às oportunidades e ameaças que lhe apresentam as regras de funcionamento do legislativo e às reações dos outros parlamentares. Mais importante, independentemente das preferências dos parlamentares, de sua identidade ou valores defendidos, essas regras acabam por moldar o comportamento dos legisladores em certos padrões, como por exemplo o provimento excessivo de políticas particularistas previsto pela teoria distributivista (WEINGAST; MARSHALL, 1983; MALTZMAN, 2001).

Para essas teorias, as instituições proveem incentivos e padrões de interação, e para compreendê-las importam os objetivos que elas permitem atingir (objetivos que também explicariam sua própria criação). As instituições, para essas teorias, são importantes pelos fins que promovem e pelo seu nível de eficácia no alcance dos objetivos dos congressistas (HALL; TAYLOR, 2003). Se, para a teoria, a finalidade das instituições é importante, esta se dá pela sua forma de organização e funcionamento, o que também conforma o processo decisório.

As teorias diferem quanto ao meio para o parlamentar atingir a reeleição. Para a teoria distributivista (WEINGAST; MARSHALL, 1983), trata-se da promoção individual do parlamentar, propiciada no ambiente das comissões descentralizadas e poderosas do Congresso dos EUA. Cada parlamentar teria uma ação significativa nas comissões que detivessem importância e relevância para seu distrito (o voto "distrital" é fundamental para explicar o funcionamento do modelo, pois fornece clara e estreita ligação entre os interesses proeminentes do distrito e a área temática da comissão legislativa).

A teoria partidária vê no fortalecimento da sigla partidária o meio para impulsionar a reeleição de seus membros (KIEWIET, MCCUBBINS, 1991). Em termos funcionais, isso seria conseguido por meio do controle, pelo partido majoritário, de instâncias decisórias estratégicas e valorização da fidelidade dos membros ao programa do partido.

A teoria informacional, em relação aos meios para promover a reeleição dos congressistas, é algo vaga, podendo-se dizer que seria a qualificação da ação parlamentar da 
casa legislativa como um todo (KREHBIEL, 1992, p.5). A principal preocupação da teoria é provar que toda a estrutura do Congresso norte-americano age para promover a produção e disseminação de informações e assim qualificar as decisões políticas diminuindo a incerteza. Deve ser considerado que no início de sua obra, Krehbiel faz várias concessões (1992, p 21 e nota de rodapé n. 30) ao acerto da perspectiva distributivista sobre a importância do particularismo nas políticas públicas, e isso faz com que fique algo incoerente a identificação desse meio promotor de reeleição na teoria informacional, porque ou as comissões atendem aos objetivos dos parlamentares individualmente (como quer a teoria distributivista), ou elas devem focar sobretudo nas necessidades informacionais da casa como um todo.

Quanto à razão para a estruturação e funcionamento dos órgãos do Legislativo, a teoria distributivista aponta a promoção de ganhos de troca. Isto é, como toda decisão depende do consentimento da maioria, as competências em matéria de políticas públicas são divididas e alocadas exclusivamente entre as comissões, e nelas os parlamentares interessados podem atuar com frequência e de forma mais relevante. É certo que os ganhos que o parlamentar individualmente consegue numa comissão têm como contrapartida sua não participação nos campos temáticos das outras comissões. Quanto ao Plenário, ele não é ativo, apenas chancela as decisões tomadas pelas comissões.

Para a teoria partidária, a estrutura organizacional da casa legislativa existiria para atender os objetivos do partido majoritário. A estrutura permite o controle e o monitoramento das atividades legislativas pelo partido, que controla o funcionamento das comissões e do Plenário.

A teoria informacional tem seu ponto forte ao explicar a razão para o desenho organizacional e o funcionamento dos órgãos legislativos. Para ela, a incerteza presente na transformação da norma escrita em fato real (entre a definição da norma e seus efeitos) é um problema generalizado no Legislativo, e a mitigação dessa incerteza se constitui em um bem público no âmbito parlamentar. Caberia às comissões, formadas por especialistas de diversas posições políticas, produzir informação útil e qualificada sobre as políticas sob sua competência e distribuí-la a todos os membros do Legislativo. Nessa estrutura, as comissões seriam órgãos subordinados ao Plenário. Interessante apontar que a lógica da divisão de trabalho e aumento da eficiência poderia explicar a gênese do sistema de comissões nos EUA, em coerência com a posição de Krehbiel. Contudo, pode-se criticar que a origem de uma instituição pode responder a uma causa e seu funcionamento contemporâneo, e assim a razão de sua permanência, a outras (MALTZMAN, 2001).

$\mathrm{Na}$ interpretação de Maltzman (2001), o que se tem nas três teorias é uma variedade de relações agente-principal (MOE, 1984) que relaciona de forma diversa órgãos do legislativo, especialmente comissões e plenário, e agentes externos. Na teoria distributivista, as comissões seriam agentes de principais colocados fora do parlamento (os deputados usariam seu lugar nas 
poderosas comissões para perseguir objetivos dos eleitores ou de outros grupos fora do legislativo). Para a teoria partidária, as comissões, e também o Plenário, seriam agentes do partido, no caso o principal. Já na teoria informacional, as comissões seriam agentes do Plenário, entregando a ele, por meio de divisão de trabalho e especialização, um bem público importante que seriam informações úteis e relevantes para a decisão sobre políticas públicas.

Como apontam Hall e Taylor (2003), a concepção de instituições para o neoinstitucionalismo da escolha racional é de que elas são criadas e perduram com o objetivo de produzir determinados efeitos - instituições, no caso legislativo, entendidas como regras de competência, desenho de órgãos e estruturas. Isso quer dizer que as instituições seriam todo o tempo avaliadas pelos congressistas, sob o risco potencial de serem alteradas para atender de forma mais eficaz os objetivos pretendidos.

$\mathrm{O}$ que então dizem as teorias neoinstitucionalistas sobre o processo decisório legislativo? Em nossa avaliação, ainda dizem pouco.

Conforme a teoria distributivista, o parlamentar adentra o Congresso com total clareza do que deve fazer para atingir o objetivo da reeleição, qual seja, atender os interesses do seu distrito com políticas particularistas. O parlamentar sabe desde o princípio quais políticas públicas o atendem, sabe identificá-las e formulá-las sem lugar à dúvida, sem custo de nenhuma natureza. Não há problematização sobre o levantamento de informações e menos ainda sobre sua avaliação. O único problema decisório do parlamentar é viabilizar sua participação relevante nos assuntos que lhe importam e conseguir apoio da maioria para seus interesses (o que é atingido pela divisão de competências entre as comissões e as regras que permitem ao parlamentar conquistar um assento seguro nas comissões de seu interesse). Mesmo nesse momento em que se decidem as políticas aprovadas pela comissão, não há problematização teórica sobre esse processo decisório; apenas se subentende que todos os parlamentares sentirse-ão atendidos pelo resultado final e realizarão uma troca mútua de apoios (logrolling).

$\mathrm{Na}$ teoria distributivista, a estrutura institucional responde a um problema de ação coletiva - como fazer com que a coletividade atenda todas as necessidades individuais. A resposta é a divisão de competências entre as comissões temáticas. Não há problema de levantamento e processamento de informação, e a única incerteza potencial é sobre se as trocas de apoio político necessárias serão possíveis. A estrutura institucional, na linha da eficácia apontada por Hall e Taylor (2003), busca tornar essa troca de apoios efetiva.

A teoria partidária mostra-se semelhante à distributivista na simplificação que faz do indivíduo e da organização. O parlamentar do modelo partidário não tem dúvidas sobre como decidir qualquer coisa, não tem necessidade de informações. A agenda partidária está clara e totalmente definida para todas as situações, sem custo, não há necessidade de coletar ou processar informações. O objetivo é viabilizar o sucesso da agenda partidária como forma de garantir seu sucesso eleitoral. Assim, a estrutura da organização é apenas uma forma de 
controlar as ações coletivas para viabilizar essa agenda partidária. Ela não provê informações ou intercâmbio entre os parlamentares, apenas permite que o partido controle momentos chave do processo monitorando fidelidade partidária e alocando partidários em postos-chaves no comando da organização.

Para as duas teorias analisadas, distributivista e partidária, não há custos de transação relativos ao levantamento e processamento de informações. Numa referência à Microeconomia, fonte de boa parte das reflexões dessas teorias, os modelos pressupõem informação perfeita (VARIAN, 2012). O único custo de transação é a coordenação das maiorias para atender os objetivos parlamentares, seja dos indivíduos ou do partido majoritário.

A teoria informacional, é mais rica na problematização do processo decisório, tanto em relação ao indivíduo quanto à organização, mas ainda assim limitada. O parlamentar, segundo essa teoria, tem apenas uma esfera de incerteza: a relação entre a norma aprovada e os efeitos que irá gerar. Não há problematização da definição de objetivos para o parlamentar ou com que ações pode atingir esses objetivos. O problema está única e exclusivamente na passagem da norma escrita ao atingimento de efeitos. Como aí encontram-se altos custos, devido ao grande número de matérias e sua complexidade, eles não são absorvidos pelos parlamentares individualmente, mas passam para a organização.

Para a teoria informacional, o Legislativo é moldado de forma a produzir informações nas comissões e distribuí-las aos membros não participantes, o que é conseguido pela reunião de especialistas (experts) - capazes de produzir informações a baixo custo - de posições políticas divergentes - quando as divergências servem de estímulo à disseminação de informações para conseguir apoio, impedindo que os especialistas se apropriem de ganhos particulares.

A teoria informacional dá pouca atenção aos vitoriosos nos processos políticos, pois ao assumir o postulado majoritário como central à análise chega a resultado inexorável: será aquela maioria de Plenário definida pela agregação de preferências após o recebimento de informações relevantes sobre as decisões (o eleitor mediano do Plenário). No caso da teoria distributivista, os vitoriosos são os membros das comissões das respectivas matérias, que detêm preferências extremadas no assunto. Para o caso da teoria partidária, o vencedor é o eleitor mediano ${ }^{2}$ do partido majoritário.

O Quadro 1 procura sintetizar as contribuições das teorias em relação aos processos decisórios legislativos.

\footnotetext{
${ }^{2}$ Eleitor mediano é um conceito baseado na análise espacial (ou algébrica) de preferências. 'Grosso modo', pode-se distribuir todos os eleitores numa escala de interesse por uma determinada política pública, os que desejam mais e os que desejam menos dela. Eleitor mediano é aquele de posição intermediária na escala, posicionado na divisão do grupo em duas metades. Por lógica, essa posição específica é que será vencedora no caso de uma eleição sobre a política pública. Cf. Hinich e Munger, 1998.
} 
Quadro 1 - Teorias e Processos Decisórios Legislativos

\begin{tabular}{|c|c|c|c|c|}
\hline \multirow[b]{2}{*}{ TEORIA } & \multicolumn{2}{|c|}{ Indivíduo } & \multicolumn{2}{|c|}{ Organização } \\
\hline & $\begin{array}{l}\text { Estrutura do } \\
\text { Processo } \\
\text { Decisório }\end{array}$ & $\begin{array}{c}\text { Processo de } \\
\text { Tomada de } \\
\text { Decisão }\end{array}$ & $\begin{array}{l}\text { Estrutura do } \\
\text { Processo } \\
\text { Decisório }\end{array}$ & $\begin{array}{c}\text { Processo de } \\
\text { Tomada de } \\
\text { Decisão }\end{array}$ \\
\hline Distributivista & $\begin{array}{lr}\text { Indivíduo } & \\
\text { atomizado, } & \text { sem } \\
\text { custo } & \text { para } \\
\text { adquirir } & \text { e } \\
\text { processar } & \\
\text { informações. } & \end{array}$ & $\begin{array}{lr}\text { Não precisa de } \\
\text { informações ou } \\
\text { análise } \\
\text { nenhuma natureza } \\
\text { (tem como dadas } \\
\text { todas as } \\
\text { informações } \\
\text { necessárias). } \\
\text { Apenas otimiza seu } \\
\text { objetivo diante dos } \\
\text { constrangimentos } \\
\text { institucionais. }\end{array}$ & $\begin{array}{lr}\text { A decisão } & \text { é } \\
\text { tomada } & \text { nas } \\
\text { comissões. } & \text { O } \\
\text { Plenário não tem } \\
\text { atuação } \\
\text { relevante. }\end{array}$ & $\begin{array}{l}\text { Não gera } \\
\text { informações } \\
\text { relevantes. A } \\
\text { lógica de } \\
\text { funcionamento } \\
\text { da organização } \\
\text { apenas garante o } \\
\text { apoio da maioria } \\
\text { aos pleitos } \\
\text { individuais. }\end{array}$ \\
\hline Partidária & $\begin{array}{lr}\text { Indivíduo } & \\
\text { atomizado, } & \text { sem } \\
\text { custo } & \text { para } \\
\text { adquirir } & \text { e } \\
\text { processar } & \\
\text { informações. } & \end{array}$ & 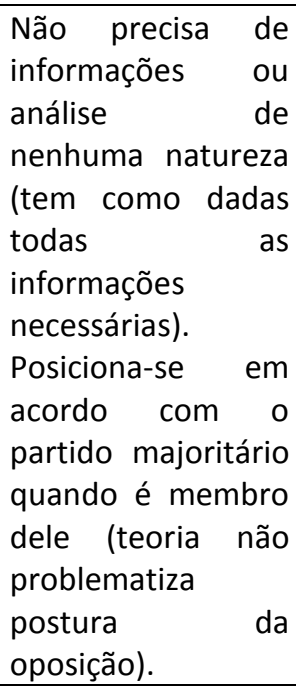 & $\begin{array}{l}\text { A decisão é } \\
\text { tomada pela } \\
\text { cúpula partidária, } \\
\text { num processo } \\
\text { exógeno ao ao } \\
\text { Legislativo. }\end{array}$ & $\begin{array}{l}\text { Não gera } \\
\text { informações } \\
\text { relevantes. A } \\
\text { lógica de } \\
\text { funcionamento } \\
\text { da organização } \\
\text { apenas garante o } \\
\text { controle do } \\
\text { partido sobre a } \\
\text { decisão. }\end{array}$ \\
\hline Informacional & $\begin{array}{lr}\text { Indivíduo } & \\
\text { atomizado, } & \\
\text { reativo } & \text { às } \\
\text { informações } & \\
\text { produzidas } & \text { pelo } \\
\text { sistema } & \text { de } \\
\text { comissões. } & \end{array}$ & $\begin{array}{lr}\text { Sua área } & \text { de } \\
\text { incerteza } & \text { está } \\
\text { localizada apenas } \\
\text { no processo de } \\
\text { translação da } \\
\text { norma escrita para } \\
\text { o mundo real, } \\
\text { sobre isso precisa } \\
\text { coletar } \\
\text { informações. }\end{array}$ & $\begin{array}{l}\text { A decisão deve } \\
\text { atender à escolha } \\
\text { do Plenário. As } \\
\text { comissões se } \\
\text { adequam a esta } \\
\text { necessidade. }\end{array}$ & $\begin{array}{l}\text { Comissões são } \\
\text { produtoras e } \\
\text { disseminadoras } \\
\text { de informações. } \\
\text { Plenário das } \\
\text { usuário } \\
\text { informações } \\
\text { produzidas. }\end{array}$ \\
\hline
\end{tabular}

Fonte: Elaboração própria

As três teorias norte-americanas sobre o funcionamento do Legislativo foram recepcionadas no Brasil e ganharam avanços diversos. Na linha distributivista, estudos fundadores são identificados com Barry Ames (2003), que postula visão de um congresso brasileiro individualista e incapaz de proporcionar governabilidade ao sistema político. Na linha informacional, poucos estudos foram realizados, valendo ressaltar os trabalhos de Santos (2003) e Santos e Almeida (2011). Em relação à teoria partidária, representada principalmente por uma série de trabalhos de Figueiredo e Fernando (FIGUEIREDO; LIMONGI, 1999), houve um grande avanço interpretativo sobre o Congresso Brasileiro. 
A interpretação de Figueiredo e Limongi é a que mais apresenta aderência aos achados empíricos relacionados ao Congresso Brasileiro nas últimas décadas, quando se assistiu a um ambiente de governabilidade razoável. Para esses autores, o caso brasileiro, embora presidencialista, aproxima-se bastante da lógica de funcionamento dos sistemas parlamentaristas, tanto na formação do governo por meio da cooptação de apoios em troca de cargos ministeriais - o 'presidencialismo de coalizão' (ABRANCHES, 1988) -, quanto no funcionamento interno do Poder Legislativo, baseado sobretudo na prevalência dos líderes e nos instrumentos legislativos do Presidente da República - capazes de em conjunto controlar a pauta legislativa e promover a aprovação de boa parte da agenda do governo.

Para fins deste artigo, o elemento principal a reter na análise da Câmara dos Deputados refere-se ao aspecto colegiado e centralizado do processo decisório legislativo. Por natureza e definição, casas legislativas têm identidade e autoridade apenas como um corpo colegiado. As decisões emanadas do Poder Legislativo, ao contrário dos Poderes Judiciário e Executivo, só tem existência se forem chanceladas pelo colegiado - que o faz de diversas formas e segue múltiplos procedimentos, mas sempre sem excluir a manifestação da maioria. Por outro lado, esses processos legislativos, da forma como presentes na Câmara dos Deputados, são centralizados.

A centralização decisória pode ser vista no papel dos líderes partidários e do Presidente da Mesa Diretora na definição da pauta do Plenário e na distribuição de recursos e oportunidades de fala e participação no processo legislativo a todos os deputados. As matérias mais importantes a tramitar na Câmara dos Deputados são enviadas ao Plenário e lá os institutos do processo legislativo que as fazem mover-se são habilitados quase exclusivamente aos líderes partidários, sendo os esforços de parlamentares individuais transpassados por dificuldades, sobretudo a lida com o tempo exíguo e a necessidade de conseguir apoiamento (apoio escrito ou verbal feito a proposições que devem contar com iniciativa coletiva). No Plenário, são feitas as deliberações finais sobre as Medidas Provisórias, as Propostas de Emenda à Constituição, os Projetos de Lei Complementar, as proposições orçamentárias, entre outras. Ainda, a relatoria de tais matérias, um importante poder alocado a um parlamentar, responde frequentemente a injunções partidárias em que têm proeminência os líderes. Excluído o Plenário, podem ser aprovados no âmbito exclusivo das comissões apenas projetos de lei no regime de apreciação conclusiva, sendo em geral matérias que atraem menor atenção.

Em termos analíticos, o que se tem na Câmara dos Deputados é a alocação do poder de agenda a um grupo seleto de parlamentares. Para Figueiredo e Limongi, poder de agenda é "a capacidade de determinar que propostas serão consideradas pelo Congresso" e "quando o serão" (FIGUEIREDO; LIMONGI, 1999, p. 23), o que se relaciona a institutos legislativos concretos como as regras de iniciativa exclusiva e mecanismos de urgência. Tanto mais centralizado é um processo decisório quanto mais significativo seja o rol de prerrogativas com impacto na agenda 
e quanto menos agentes possuam essas prerrogativas.

Embora o Legislativo brasileiro afaste-se do padrão estadunidense - entre outros fatores pela multiplicidade de partidos e menor separação de poderes no Brasil -, foi por meio dos trabalhos de Figueiredo e Limongi que se viram aplicados no Brasil os fundamentos da teoria partidária. Em termos do processo decisório, o que se tem então no Brasil é um colegiado com alocação de poder e influência na mão de poucos, cabendo aos líderes e ao Presidente da Mesa Diretora o papel principal naquilo que podemos chamar de modelo decisório colegiadocentralizado.

\section{Visão Teórico-Exemplificativa do Processo Decisório}

Ao se focar o processo de tomada de decisão, não se pode deixar de vislumbrar sua complexidade em função do contexto e das variáveis a ele associados. Porém, de forma a se poder apropriar de instrumentos que permitam compreendê-lo (ainda que não totalmente) e utilizar ferramentas para utilizá-lo ou aperfeiçoá-lo, assume-se posição reducionista, trazendo ao estudo apenas elementos já consagrados na literatura.

Parte-se do princípio de que a tomada de decisão é um processo que envolve adotar uma ação no momento, visando a uma resposta ou resultado futuro (SIMON, 1960). Do enunciado, alguns elementos são marcantes, quais sejam:

a) Processo: a tomada de decisão envolve fases, desde a concepção ou aproximação com o problema, até a efetiva decisão; ainda que, em alguns casos, se pense em um processo cíclico (com retroalimentação), a tomada de decisão segue etapas sucessivas que levam a um resultado;

b) Ação no momento: significa dizer que a tomada de decisão é temporal e ocorre quando opções são apresentadas em determinado instante; e,

c) Resultado futuro: o objetivo da decisão é alcançar algo além do momento em que foi assumida.

Por desdobramento, outros fatores começam a surgir do princípio anteriormente apresentado e que delineia melhor a tomada de decisão:

a) Existência de opções: a tomada de decisão tem por premissa o fato de que há opções de escolha, ou seja, a decisão implica em adotar-se um caminho diante de outro (ou outros); no caso a decisão mais simples implica em manter-se o status quo ou mudá-lo, indicando a existência de opção alternativa;

b) Temporalidade: a tomada de decisão é um fenômeno eminentemente temporal, marcando uma diferença na situação antes e depois da escolha realizada, ainda que esta se restrinja à manutenção do status quo (que passa a ser admitido como a opção escolhida por mais tempo).

Pode-se representar o processo de tomada de decisão a partir dos elementos 
anteriormente assinalados da seguinte forma (Figura 1):

Figura 1 - Elementos da Tomada de Decisão
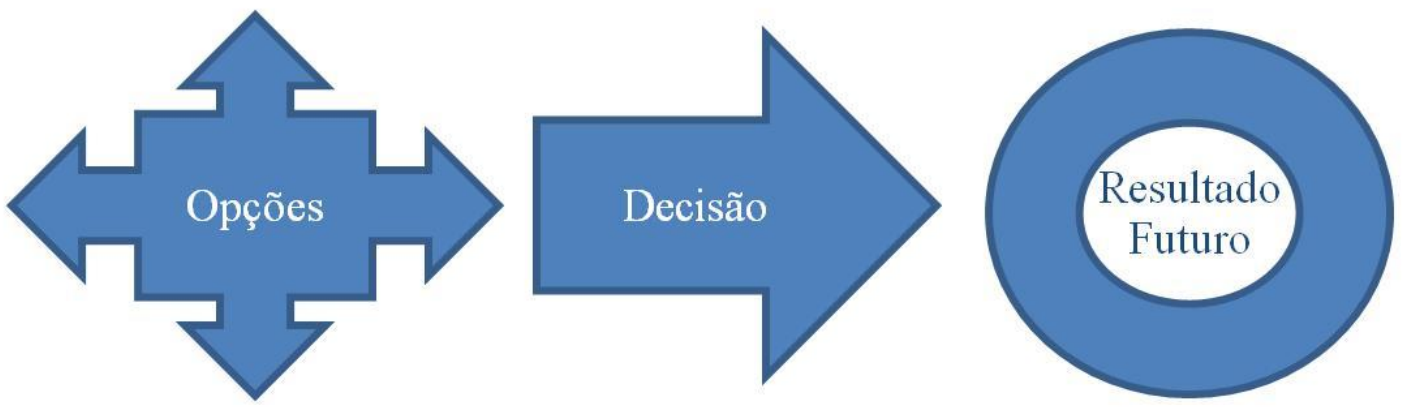

Tempo

Fonte: Elaboração própria

Exemplifica-se a situação, de forma simples, ao admitir o parlamentar escolhendo, entre alternativas de ação para uma proposição, aquela que melhor se adequa a um resultado esperado, sendo que, nesse caso, há variáveis que influenciam na determinação das opções (interesses diversos, pressões de grupos, decisões de partidos etc.), na decisão (individual ou coletiva) e resultado futuro (visibilidade, reeleição etc.)

Tomada dessa forma, a decisão pode ser classificada de acordo com o nível organizacional em que ocorre (FREITAS; KLADIS, 1995). Assim, tem-se a decisão tomada em níveis diferenciados da organização, por exemplo, no nível operacional, em que as decisões tendem a ser mais estáveis e as opções adotadas baseadas na comparação com situações anteriores. Nesse caso, por exemplo, a tramitação de uma proposição ou a dúvida sobre o encaminhamento a uma determinada Comissão Parlamentar tem a escolha descrita em regimento ou segue trâmite já adotado em outras situações. Passando-se ao nível tático, as decisões tendem a se caracterizar por aumento de complexidade e que buscam atender a atuação gerencial, mormente de acompanhar, controlar e avaliar. Situação que se exemplifica pela tomada de decisão de um Secretário de Comissão Parlamentar ao organizar as informações a serem repassadas ao presidente da comissão, considerando suas características e necessidades particulares e pessoais. Em último nível, as decisões estratégicas (MIRANDA, 1999, 2004), que têm no ambiente externo sua principal influência, povoado de variáveis complexas, múltiplas e não controláveis, e que determinam grandes ações ou destinos da organização. A decisão tomada no plenário da Câmara dos Deputados, sobre matéria de grande interesse da população, sofre influência de grupos de pressão, da mídia, dos presentes nas galerias durante as votações etc.

Além do nível organizacional, interessa notar que as decisões, lato sensu, apresentam características que permitem avaliar sua complexidade e extensão, conforme se observa no 
quadro 2 .

Quadro 2 - Características do Processo Decisório e Exemplificação no Legislativo

\begin{tabular}{|c|c|c|c|}
\hline Característica & Descrição & Variação & $\begin{array}{c}\text { Exemplo no } \\
\text { Legislativo } \\
\end{array}$ \\
\hline Estrutura & $\begin{array}{l}\text { Possibilidade de organizar os } \\
\text { elementos da tomada de } \\
\text { decisão, identificando fatores } \\
\text { intervenientes, atores e } \\
\text { processos envolvidos }\end{array}$ & $\begin{array}{l}\text { Quanto mais } \\
\text { estruturada, mais } \\
\text { objetiva e simples é a } \\
\text { escolha na decisão }\end{array}$ & $\begin{array}{l}\text { Organização de } \\
\text { reunião plenária em } \\
\text { uma Comissão } \\
\text { Parlamentar para } \\
\text { discussão de matéria } \\
\text { trivial }\end{array}$ \\
\hline Certeza & $\begin{array}{l}\text { Nível de segurança quanto ao } \\
\text { acerto da opção escolhida }\end{array}$ & $\begin{array}{l}\text { A certeza é } \\
\text { inversamente } \\
\text { proporcional ao nível } \\
\text { hierárquico onde ocorre } \\
\text { a decisão }\end{array}$ & $\begin{array}{l}\text { Decisões tomadas no } \\
\text { Plenário da Casa } \\
\text { Legislativa, que } \\
\text { envolvem questões } \\
\text { estratégicas e de alto } \\
\text { impacto têm maior } \\
\text { nível de incerteza que } \\
\text { decisões } \\
\text { administrativas de } \\
\text { compras de passagens } \\
\text { aéreas, por exemplo }\end{array}$ \\
\hline Repetitividade & $\begin{array}{l}\text { Possibilidade de replicar o } \\
\text { modo de escolha de opções em } \\
\text { situações similares }\end{array}$ & $\begin{array}{l}\text { A repetitividade é } \\
\text { maior quanto menores } \\
\text { forem as opções de } \\
\text { escolha e menor o nível } \\
\text { organizacional }\end{array}$ & $\begin{array}{l}\text { A instrução e o } \\
\text { encaminhamento de } \\
\text { processos é atividade } \\
\text { administrativa de alta } \\
\text { repetitividade }\end{array}$ \\
\hline Previsibilidade & $\begin{array}{l}\text { Possibilidade de se estabelecer } \\
\text { os resultados ou as } \\
\text { consequências possíveis para } \\
\text { cada opção no processo } \\
\text { decisório }\end{array}$ & $\begin{array}{l}\text { Quanto mais se conhece } \\
\text { o comportamento das } \\
\text { variáveis envolvidas no } \\
\text { processo decisório, } \\
\text { maior a tendência de se } \\
\text { prever o resultado ou as } \\
\text { consequências da } \\
\text { decisão }\end{array}$ & $\begin{array}{l}\text { Uma proposição } \\
\text { legislativa que vise a } \\
\text { ampliar a aplicação } \\
\text { de recursos em saúde } \\
\text { e educação tem a } \\
\text { tendência a ser } \\
\text { melhor recebida pela } \\
\text { mídia e pela } \\
\text { sociedade, sendo, } \\
\text { portanto, seus } \\
\text { resultados } \\
\text { relativamente } \\
\text { previsíveis }\end{array}$ \\
\hline Programação & $\begin{array}{l}\text { Existência de um conjunto de } \\
\text { procedimentos pré- } \\
\text { estabelecidos que levam a uma } \\
\text { decisão }\end{array}$ & $\begin{array}{l}\text { Quanto mais } \\
\text { programadas maior o } \\
\text { nível de certeza da } \\
\text { decisão e maior a sua } \\
\text { previsibilidade }\end{array}$ & $\begin{array}{l}\text { O rito do processo } \\
\text { legislativo tende a ser } \\
\text { uma sequencia de } \\
\text { ações e decisões que } \\
\text { ocorrem com alto } \\
\text { grau de } \\
\text { previsibilidade. Não } \\
\text { se garante aqui o } \\
\text { resultado da decisão, } \\
\text { mas a sua ocorrência } \\
\text { (Deve-se considerar } \\
\text { também a não decisão } \\
\text { como decisão de } \\
\text { veto.) }\end{array}$ \\
\hline
\end{tabular}




\begin{tabular}{|l|l|l|l|}
\hline Característica & \multicolumn{1}{|c|}{ Descrição } & \multicolumn{1}{c|}{ Variação } & \multicolumn{1}{c|}{$\begin{array}{c}\text { Exemplo no } \\
\text { Legislativo }\end{array}$} \\
\hline Racionalidade & $\begin{array}{l}\text { Possibilidade de uso de } \\
\text { elementos quantitativos na } \\
\text { tomada de decisão, avaliando } \\
\text { meios e resultados e buscando } \\
\text { maximizá-los }\end{array}$ & $\begin{array}{l}\text { Quanto maior a } \\
\text { racionalidade, maior o } \\
\text { grau de certeza e de } \\
\text { previsibilidade de } \\
\text { resultados da decisão }\end{array}$ & $\begin{array}{l}\text { Definições do } \\
\text { orçamento público }\end{array}$ \\
\hline
\end{tabular}

Fonte: Elaboração própria baseada, exemplificada e ampliada a partir de Freitas e Kladis (1995)

Outra questão pertinente ao estudo refere-se ao nível de centralização das decisões. No caso, há filtros de informação em cada nível hierárquico decisório, o que torna a tomada de decisão de alto nível 'viesada' pelas escolhas que os decisores intermediários fizeram. Nesse caso, quando se vê decisão realizada colegiadamente no plenário da Câmara dos Deputados, por exemplo, há que se considerar a importância do filtro político (ANSOFF, 2009) - visando especialmente a interesses partidários e pessoais, Teorias Partidária e Distributivista - que uma efetiva partilha de informações geradoras de decisão (Teoria Informacional). Interessante destacar o pensamento de Mintzberg (2012) a respeito ao se pronunciar quanto à descentralização da tomada de decisão.

... um processo de decisão é mais descentralizado quanto o tomador de decisão controla apenas a fase de escolha (o mínimo que pode fazer a ainda ser chamado de tomador de decisão). Na hierarquia organizacional, ele perde algum poder para quem coleta a informação, para seus conselheiros ao lado, para quem autoriza no nível acima e para os executores no nível abaixo (MINTZBERG, 2012, p. 119).

\section{Modelos de Tomada de Decisão e o Legislativo}

Os modelos de tomada de decisão, 'grosso modo', privilegiam aspectos diferenciados do processo decisório, ora enfatizando o uso de recursos quantitativos, ora ressaltando os elementos intervenientes. No contexto desse estudo, serão trazidos os modelos de processo decisório consolidados por Bethlem (1987) conjugados com o modelo de Choo (2003) e Lousada e Valentim (2011), por apresentarem significância e aplicabilidade ao Poder legislativo. O quadro 3 resume as características principais de cada modelo, apresentando-os de acordo com seu criador ou sua área e indicando as fases constituintes do processo de decisão e/ou características que os diferenciam dos demais.

Quadro 3 - Características principais dos modelos decisórios

\begin{tabular}{|l|l|}
\hline \multicolumn{1}{|c|}{ Modelo } & \multicolumn{1}{c|}{ Processo e/ou Características } \\
\hline Simon & $\begin{array}{l}\text { Apresenta 4 etapas: (i)avaliação da situação (inteligência), (ii)análise de linhas de } \\
\text { ação (projeto ou design), (iii)tomada de decisão (escolha) e (iv)avalição de escolhas } \\
\text { passadas (revisão). }\end{array}$ \\
\hline Militar & $\begin{array}{l}\text { Apresenta 5 etapas: (i)definição da missão (objetivo a ser alcançado com a decisão); } \\
\text { (ii)descrição da situação e das possíveis ações; (iii)avaliação das diferentes linhas de } \\
\text { ação quanto a aceitabilidade (consequências das ações), exequibilidade } \\
\text { (possibilidade de execução) e adequação (ajuste ao objetivo); (iv)avaliação } \\
\text { comparada das linhas de ação (fortalezas e fraquezas próprias e do inimigo); v) } \\
\text { decisão }\end{array}$ \\
\hline
\end{tabular}




\begin{tabular}{|c|c|}
\hline Modelo & $\begin{array}{l}\text { Processo e/ou Características } \\
\end{array}$ \\
\hline $\begin{array}{l}\text { Kepner \& } \\
\text { Tagore }\end{array}$ & $\begin{array}{l}\text { O modelo racional é o mais complexo. Envolve } 4 \text { fases que se subdividem: (i)análise } \\
\text { da situação, envolvendo a listagem das preocupações, a separação dos elementos } \\
\text { confusos e caóticos, priorização (gravidade, urgência e tendência), e colocação em } \\
\text { ação; (ii) análise do problema, envolvendo a definição do problema, sua distinção em } \\
\text { relação a outros problemas, mudanças provocadas, possíveis causas do problema e } \\
\text { teste e verificação das causas; (iii) análise de decisões, envolvendo a determinação e } \\
\text { classificação de objetivos, o desenvolvimento, a avaliação, a escolha de uma } \\
\text { alternativa; avaliação das consequências adversas da tentativa de decisão (simulação } \\
\text { ponderada por probabilidade e gravidade) e escolha final; e, finalmente, (iv) análise } \\
\text { de problemas potenciais, envolvendo a identificação de áreas críticas, problemas } \\
\text { potenciais, causas dos problemas potenciais, ações preventivas e contingentes e um } \\
\text { sistema de alarme. }\end{array}$ \\
\hline $\begin{array}{l}\text { Pesquisa } \\
\text { Operacional }\end{array}$ & $\begin{array}{l}\text { Apresenta } 6 \text { etapas: (i) formulação do problema; (ii) construção do modelo } \\
\text { matemático e escolha da técnica (programação linear, programação dinâmica, } \\
\text { programação de integers, teoria dos jogos, teoria das filas, teoria dos grafos, teoria } \\
\text { bayesiana e teoria da probabilidade) (iii) encontro da solução por meio do modelo; } \\
\text { (iv) teste do modelo e da solução; (v) estabelecimento de controles sobre a solução; } \\
\text { (vi) colocação da solução em uso }\end{array}$ \\
\hline CPSI & $\begin{array}{l}\text { O modelo do Creative Problem Solving Institute (CPSI) apresenta } 5 \text { fases: (i) } \\
\text { identificação do contexto do problema; (ii) definição do problema; (iii) identificação } \\
\text { de ideias (uso de brainstorming para identificação de possíveis alternativas de } \\
\text { solução); (iv) definição de soluções; (v) aceitação de soluções (decisão, escolha final, } \\
\text { planejamento de ação e ação) }\end{array}$ \\
\hline Guilford & $\begin{array}{l}\text { O modelo criativo e judicial apresenta } 4 \text { fases: na linha criativa (i)filtro (foco no } \\
\text { problema); (ii) conhecimento (exame e estrutura do problema); e (iii) produção } \\
\text { (geração de ideias) e, paralelamente, na linha judicial (v) avaliação (testes de } \\
\text { respostas e ideias) }\end{array}$ \\
\hline Mintzberg & $\begin{array}{l}\text { Apresenta } 3 \text { fases: (i) identificação (reconhecimento de decisão e diagnose); (ii) } \\
\text { desenvolvimento (procura e projeto); (iii) seleção (separação, avaliação/escolha) }\end{array}$ \\
\hline Bethlem & $\begin{array}{l}\text { O modelo genérico de Bethlem leva em consideração as similaridades entre os } \\
\text { demais modelos e apresenta } 4 \text { fases: (I) decisão de decidir; (ii) definição do foco da } \\
\text { decisão; (iii) formulação de alternativas; (iv) escolha de alternativas }\end{array}$ \\
\hline Choo & $\begin{array}{l}\text { O modelo de ambiguidade e incerteza de Choo é composto de } 4 \text { modelos, com fases } \\
\text { diferenciadas: } \\
\text { a) Modelo racional: (i) coleta de informações; (ii) análise das informações; (iii) } \\
\text { identificação de alternativas; (iv) escolha; (v) adoção da alternativa } \\
\text { b) Modelo processual: (i)identificação da necessidade de decisão; (ii) } \\
\text { desenvolvimento de soluções; (iii) seleção/escolha } \\
\text { c) Modelo anárquico: não há fases a serem seguidas } \\
\text { d) Modelo político: não há fases definidas, sendo que as decisões são resultados } \\
\text { de negociações, uma vez que os objetivos e interesses tendem a ser } \\
\text { conflitantes }\end{array}$ \\
\hline Orgânico & $\begin{array}{l}\text { Apresenta } 3 \text { fases: } 1^{\text {a }} \text { fase - identificação dos fluxos informacionais e documentais, } \\
\text { mapeamento e monitoramento, aplicação de questionários, entrevistas estruturas e } \\
\text { semiestruturadas; } 2^{\mathrm{a}} \text { fase - disseminação, acesso e uso, níveis de classificação e } \\
\text { acesso, banco/base de dados de informação orgânica; } 3^{\text {a }} \text { fase - memória institucional }\end{array}$ \\
\hline
\end{tabular}

Fonte: Elaboração própria baseada, exemplificada e ampliada a partir de Bethlem (1987); Choo (2003) e Lousada e Valentim (2011)

Para que se possa vislumbrar a aplicabilidade dos modelos a situações, órgãos e estruturas do Legislativo, necessário se faz apresentar as principais instâncias decisórias desse Poder, ainda que sejam focados apenas os elementos da esfera federal, uma vez que são exemplificativos e permitem replicações para as demais esferas. Assim, Gomes (2011) identifica 6 instâncias de decisão do Congresso Nacional, entendidas como "aquelas onde ocorrem as interações entre os atores para deliberarem (em geral, pública e formalmente) sobre 
as posições legislativas" (GOMES, 2011, p. 56). São elas o plenário e as comissões (permanentes e temporárias) do Congresso Nacional, do Senado Federal e Câmara dos Deputados. Porém, outras instâncias serão agregadas nesse texto, em virtude de representarem, com maior clareza, locais de aplicação dos modelos de decisão indicados no Quadro 3.

Verifica-se que os modelos de Simon, Mintzberg e Bethlem são genéricos e similares e têm sua aplicabilidade em todas as instâncias decisórias. Observa-se que as fases de avaliação e análise de linhas de ação costumam ocorrer, em muitos casos, antes das discussões em plenário, nos gabinetes parlamentares, nos encontros de líderes e nas lideranças. Já o modelo militar tende a ser utilizado em situações em que temas polêmicos são discutidos. Grupos de pressão (lobby) tendem a influenciar os parlamentares no sentido a adotar ou não determinada decisão quando a proposição é colocada em debate. Nesse caso, os representantes são municiados de informações sobre vantagens e desvantagens da adoção de determinada medida, bem como são apresentadas simulações sobre as consequências de adoção de cada opção. O modelo de Kepner $\&$ Tagore se assenta com primazia nos trabalhos desenvolvidos pelas Comissões Parlamentares de Inquérito, tendo em vista sua complexidade e do cuidado com as recomendações advindas dos resultados de seus trabalhos. Ainda que não sejam utilizadas técnicas para avaliação dessas consequências, o trabalho nas CPIs envolve a detida análise dos desdobramentos de suas ações. O modelo de pesquisa operacional é o menos observado no Legislativo, utilizado para possíveis simulações de alocação de recursos nas discussões do orçamento público. A seu turno, o modelo CPSI tem seu lugar em reuniões de líderes de partidos, quando se procura identificar alternativas por meio da apresentação de ideias pelos representantes de cada partido envolvido com o tema. Igualmente, às CPIs aplica-se o modelo de Guilford, considerando ser imperioso avaliar constantemente os 'achados' do processo investigatório, intrínseco à atividade da comissão.

O modelo de Choo merece atenção especial, considerando suas constituições e peculiaridades. Os modelos racional e processual aproximam-se dos modelos genéricos anteriormente citados (Simon, Mintzberg e Bethlem) e aplicam-se a todas as instâncias. O modelo anárquico, por suas características intrínsecas, pode ocorrer em qualquer instância ou momento. Porém, o modelo político é o mais observável, particularmente no comportamento parlamentar enquanto profissional voltado para a 'perpetuação' de sua atividade legislativa, conforme o que preconiza a Teoria Distributivista. É no modelo político que se vislumbra com clareza a posição decisória do parlamentar.

Finalmente, o modelo orgânico é o que mais se aproxima da Teoria Informacional. Nele estão fundadas as ações voltadas para a busca constante de informações para a tomada de decisões. Nesse contexto, integram informações orgânicas (LOUSADA; VALENTIM, 2011) como é o caso de domínio do processo legislativo, definido seu rito nos regimentos internos e complementado por questões de ordem e outros recursos - e informações estratégicas 
(MIRANDA, 1999), obtidas do meio externo às Casas Legislativas e que integram decisões sobre temas discutidos em seu âmbito.

\section{Tipos e elementos de estrutura organizacional e as Casas Legislativas}

Abordando aspectos de estrutura organizacional que influenciam no processo decisório, interessante assinalar os elementos destacados por Mintzberg (2012), estabelecendo-se o paralelo exemplificativo com uma casa legislativa: a Câmara dos Deputados. A escolha do estudo de Mintzberg está em sua universalidade e na proposta de desmistificar a consideração leiga corrente no ambiente da Câmara dos Deputados de que suas características são sui generis e não podem ser comparadas a outras organizações, principalmente as privadas.

Em se tratando de autoridade formal, elemento clássico de estruturas organizacionais, observa-se que as Casas Legislativas valem-se de dois modelos: o primeiro, voltado para a condução dos assuntos administrativos, apresentando estrutura verticalizada de comando e autoridade bem definida, desde o Diretor Geral e do Secretário Geral até os chefes de seções (como no caso da Câmara dos Deputados); o segundo, voltado para as decisões colegiadas, nas quais cada parlamentar tem igual opção e peso de voto (não se considerando os jogos de poder e interesses) e que são representadas pelos debates e deliberações em plenário ou em comissões.

Outro aspecto organizacional refere-se à definição de processos. Verifica-se que os processos organizacionais nas Casas Legislativas são regidos, mais uma vez, pela dicotomia entre administrativo e legislativo. O primeiro segue os cânones da burocracia clássica, com a existência de processos administrativos controlados por sistemas e que geram dossiê, na Câmara dos Deputados, comumente conhecido como "pasta rosa”. Já o processo legislativo é orientado pelos Regimentos Internos de cada casa, sendo influenciados por questões de ordem e outras 'manobras políticas' que alteram seu curso em função e contextos, situações e interesses específicos.

Avaliando a questão da comunicação, o sociograma (SELLTIZ, 1974) do contexto legislativo aponta os diversos tipos de comunicação: vertical, seguindo a linha formal de comunicação, com o suporte do processo administrativo ou legislativo; horizontal, representado pelo repasse de informações entre parlamentares de um mesmo partido ou de partidos coligados (por exemplo); e transversal, quando os parlamentares solicitam apoio administrativo para atividades de compra e suprimento de materiais a áreas administrativas da Casa Legislativa, sem que esse procedimento deva necessariamente seguir a linha hierárquica formal. Destaca-se, ainda, que a comunicação informal ocorre em todos os níveis e observa-se sua relevância ao se tratar das questões de lobby (FARHAT, 2007) no contexto legislativo.

Cumpre ainda focar o processo de gestão da informação do ambiente legislativo, no qual os estilos identificados por McGee e Prusak (1994) são notadamente identificados. O primeiro é o modelo monárquico, em que há um gestor 'soberano' que detém informação 
privilegiada e a utiliza em momentos de decisão superior, como é o caso do Secretário Geral da Mesa e do próprio Presidente da Câmara dos Deputados. O modelo feudal, representado pelo sigilo e guarda de informação que, ainda não considerada privilegiada, é tratada como tal. É o caso de informações sobre salários e outras que tramitam no sistema legislativo. Com a Lei de acesso à Informação (BRASIL, 2011), o feudalismo informacional nessa área foi reduzido, abrindo espaço para o modelo democrático tomar lugar, sendo sua característica a partilha ampla e irrestrita de informações. O modelo da utopia democrática, que postula a existência de sistema informatizado como recurso que suplanta qualquer necessidade de informação, ignorando o comportamento informacional do usuário. Fato de destaque a ser citado seria o painel eletrônico do Senado Federal, que, embora gerido e mantido com tecnologias de segurança avançadas, não evitou o episódio da burla de votação em 2000 (BRASIL, 2012). Por fim, o modelo anárquico em que as informações são geradas e geridas sem controle: as comunicações informais nas casas legislativas alimentam esse tipo de modelo.

Caracterizando a estrutura organizacional segundo as cinco partes básicas propostas por Mintzberg (2012), tem-se o descrito no Quadro 4:

Quadro 4 - Partes Básicas da Organização Legislativa

\begin{tabular}{|l|l|l|}
\hline \multicolumn{1}{|c|}{ Parte Básica } & \multicolumn{1}{|c|}{ Descrição } & \multicolumn{1}{|c|}{$\begin{array}{c}\text { Exemplo na Organização } \\
\text { Legislativa }\end{array}$} \\
\hline $\begin{array}{l}\text { Núcleo } \\
\text { operacional }\end{array}$ & $\begin{array}{l}\text { Assegura as entradas da produção; realiza } \\
\text { os processos de transformação; distribui } \\
\text { os resultados/produtos; fornece apoio } \\
\text { direto às partes }\end{array}$ & $\begin{array}{l}\text { Coordenações e seções } \\
\text { administrativas } \\
\text { Comissões parlamentares }\end{array}$ \\
\hline $\begin{array}{l}\text { Cúpula } \\
\text { estratégica }\end{array}$ & $\begin{array}{l}\text { Assegura o cumprimento da missão; } \\
\text { atende às necessidades dos stakeholders }\end{array}$ & $\begin{array}{l}\text { Plenário, Secretaria Geral da } \\
\text { Mesa } \\
\text { Colégio de Líderes }\end{array}$ \\
\hline $\begin{array}{l}\text { Linha } \\
\text { intermediária }\end{array}$ & $\begin{array}{l}\text { Representada pelo gerentes } \\
\text { intermediários, que realização a } \\
\text { supervisão e feedback }\end{array}$ & $\begin{array}{l}\text { Diretores de Centros e órgãos } \\
\text { de mesmo nível, Secretários de } \\
\text { Comissões }\end{array}$ \\
\hline Tecnoestrutura & Padroniza métodos e procedimentos & $\begin{array}{l}\text { Assessoria de Planejamento e } \\
\text { Gestão, Centro de Formação, } \\
\text { Aperfeiçoamento e } \\
\text { Treinamento (competências } \\
\text { organizacionais) } \\
\text { Assessorias Legislativas }\end{array}$ \\
\hline $\begin{array}{l}\text { Assessoria de } \\
\text { apoio }\end{array}$ & $\begin{array}{l}\text { Unidades especializadas de apoio à } \\
\text { organização fora de seu fluxo operacional }\end{array}$ & $\begin{array}{l}\text { Serviços de Administração na } \\
\text { Câmara dos Deputados }\end{array}$ \\
\hline
\end{tabular}

Fonte: Elaboração própria baseada e exemplificada Mintzberg (2012)

Além das partes básicas, Mintzberg (2012) propõe a configuração básica de estrutura de uma organização. No caso do Legislativo, observa-se predominância das características da burocracia mecanizada, que enfatiza a padronização de processos e a tecnocracia, tanto no contexto administrativo, quanto no legislativo. Contudo, não se pode ignorar a existência de estruturas singularmente adhocráticas - caso das comissões parlamentares de inquérito - e da busca de transformação em burocracia profissional, enfatizando o gerencialismo (BRESSERPEREIRA, 1996) como forma de modernização da máquina legislativa. 
Em termos de estrutura legislativa, observa-se que há, na cultura organizacional, clara divisão entre área legislativa - considerada área fim e voltada para a formulação das leis, a representação política e fiscalização do Poder Executivo - e a área administrativa, voltada para suporte às atividades legislativas. Porém, tal segregação implica em desenvolvimento equivocado de ações parciais que não atingem a Casa como um todo, promovendo dissonâncias nos processos decisórios e de gestão. Essas questões são reforçadas por Miranda (2011), quando analisa a instituição do planejamento estratégico somente para a área administrativa da Câmara dos Deputados e argumenta:

\begin{abstract}
Considerando-se que as decisões que impactam a direção da Casa partem da esfera legislativa (em princípio pelo Presidente da Câmara dos Deputados em conjunto com a Mesa Diretora e os próprios deputados), a concepção de uma gestão estratégica da área administrativa aproxima-se da visão de Michel E. Porter quanto ao conceito de eficiência operacional, o qual estabelece que a adoção de ferramentas de aprimoramento administrativo não garante o alcance de objetivos estratégicos que distinguem a atuação da organização em seu ambiente (PORTER, 2006). Desta feita, para a adequada gestão da informação estratégica, impactante da formulação e da decisão estratégica, é importante que ambas as áreas que compõem a CD partilhem de um mesmo plano estratégico de ações, não dissociado, único (MIRANDA, 2011, p. 153).
\end{abstract}

\title{
7 Conclusão
}

A experiência adquirida na disciplina Estrutura Organizacional e Processo Decisório Legislativo, e as reflexões empreendidas neste artigo, indicam que há importantes ganhos potenciais numa abordagem interdisciplinar do funcionamento do legislativo, aqui especificamente seu processo decisório. A limitação da análise da Ciência Política deixa encoberta a natureza dos processos específicos que moldam a atividade e o cotidiano dos parlamentares. Modelos decisórios de várias naturezas são utilizados amplamente nas atividades do Legislativo, em que variam fortemente os contextos de previsibilidade, o número de decisores e as matérias sob análise.

O processo político pode, e muitas vezes deve, contar com elementos de ineditismo, novidade e liberdade, e de fato soluções que constroem consensos e abrem portas à paz social e ao desenvolvimento são sempre processos criativos, carregados de ousadia e coragem. Por outro lado, não se deve enganar com uma perspectiva desprovida de foco e olhar analítico, em que se acredita que a autoridade dos eleitos, por si mesma, pode sempre fundar novas regras e procedimentos. Nada mais distinto do que ocorre nos ambientes legislativos.

As casas legislativas são organizações que transformam em rotinas e procedimentos situações políticas que se repetem com frequência.. A estruturação de caminhos para deliberação, a limitação do número de atores relevantes, a alocação de recursos do processo decisório em certo número de agentes fazem com que as decisões sejam factíveis, legitimadas pelo processo e em boa medida previsíveis.

Assim como outras organizações, o legislativo é composto por subunidades, que podem 
decompor-se até o nível do indivíduo, que deveriam alinhar-se aos objetivos finais dessa mesma organização. Cada uma destas subunidades, que na Câmara podem ser comissões, plenário, Mesa Diretora, colégio de líderes, deputados, etc., funcionam sob processos decisórios particulares, moldados a sua natureza, suas possibilidades e seus interesses. Não há singularidade nisto. O que diferencia a Câmara dos Deputados em relação a outras organizações é que a seleção de seus membros é feita à revelia dos objetivos e da lógica da instituição. Enquanto empresas têm política de recursos humanos e escolhem quem melhor se alinhe a seus objetivos, sempre promovendo mecanismos de avaliação entre as estratégias particulares de cada subunidade e o objetivo final da organização, na Câmara dos Deputados seus membros são selecionados por meio de um processo autônomo em relação ao próprio legislativo, as eleições. Os membros escolhidos portam, em geral, sua própria visão sobre o legislativo e têm seus próprios objetivos, que podem estar inclusive em contradição com o objetivo da instituição. É nesse sentido que a lógica colegiada-centralizada dos processos decisórios demonstra uma de suas facetas: a centralização é um dos caminhos possíveis para dar um rumo às ações da Câmara dos Deputados. Se melhor ou pior que uma direção descentralizada não se pode afirmar, mas com certeza diferente e mais previsível para as forças políticas (as direções partidárias e o Poder Executivo).

Assim, determinar modelo único de decisão que melhor configure o processo decisório de uma Casa Legislativa como a Câmara dos Deputados seria arriscado e inadequado, considerando-se que, em diferentes instâncias e situações, modelos diversos podem ser utilizados a fim de explicar os fenômenos decisórios que ocorrem no seio do legislativo. Estudos mais aprofundados se delineiam e abrem espaço para a melhor compreensão das facetas decisórias do contexto legislativo, lançando-se mão de teorias de Ciências que se complementam e se integram, mostrando a inter, trans e multidisciplinaridade reinante no Poder Legislativo.

\section{Referências}

ABRANCHES, S. H. H. Presidencialismo de Coalizão: o dilema institucional brasileiro. Dados - Revista de Ciências Sociais. Rio de Janeiro, vol. 31, n. 1, 1988, p. 5-34.

AMES, B. Os entraves da democracia no Brasil. Rio de Janeiro: FGV, 2003. Ann Arbor: The University of Michigan Press. 2001.

BETHLEM, A S. Modelos de processo decisório. Revista de Administração. São Paulo, v. 22, n.3, 1987.

BRASIL. Palácio do Planalto. Lei $\mathbf{n}^{\mathbf{0}}$ 12.527, de 18 de novembro de 2011. Disponível em: <http://www.planalto.gov.br/ccivil_03/_ato2011-2014/2011/lei/112527.htm>. Acesso em: 28 nov. 2013.

BRASIL. Poder Judiciário. Processo n. 2001.34.00.026152-5/7300. Justiça Federal. 20ª Vara Federal. Ação de Improbidade Administrativa. Juiz Federal: Alexandre Vidigal de Oliveira. $\begin{array}{lllll}\text { Congresso em } & \text { foco. Brasília, } 2012 . & \text { Disponível em: }\end{array}$ 
$<$ http://congressoemfoco.uol.com.br/operacao-caixa-de-pandora/integra-da-sentenca-quecondena-jose-roberto-arruda/>. Acesso em: 28 nov. 2013.

BRESSER-PEREIRA, L. C. Administração pública gerencial: estratégia e estrutura para um novo Estado. Texto para Discussão n.9. Brasília, MARE/ENAP, 1996.

CHOO, C. W. A Organização do Conhecimento. São Paulo: Editora SENAC São Paulo, 2003.

DAGNINO, R. et alii: Gestão estratégica da inovação: metodologias para análise e implementação. Taubaté, Editora Cabral Universitária, 2002. Disponível em: <http://www.oei.es/salactsi/rdagnino1.htm>. Acesso em: 28 nov. 2013.

DOWNS, A. Uma teoria econômica da democracia. 1.reimpr. ed. São Paulo: Edusp, 2013. ((Clássicos, 15)).

FARHAT, S. Lobby: O que é, como se faz, ética e transparência na representação junto a governos. São Paulo: Aberje, 2007.

FENNO, R. F. Congressmen in committees. Boston: Little, Brown, 1973.

FIGUEIREDO, A. C.; LIMONGI, F. Executivo e legislativo na nova ordem constitucional. Rio de Janeiro: Fundação Getúlio Vargas: Fapesp, 1999.

FREITAS, H.; KLADIS, C. M. O processo decisório: modelos e dificuldades. Revista Decidir. a. II. n. 8. Rio de Janeiro, mar. 1995. p. 30-34.

GOMES, F. B. C. Interações entre o Legislativo e o Executivo Federal do Brasil na definição de políticas de interesse amplo: uma abordagem sistêmica, com aplicação na saúde. Tese. Doutorado em Sociologia e Ciência Política. Rio de Janeiro: Universidade Estadual do Rio de Janeiro, 2011. 337 p. Disponível em: <http://bd.camara.gov.br/bd/handle/bdcamara/6165>. Acesso em: 25 Set. 2012.

GONTIJO, A. C.; MAIA, C. S. C. Tomada de decisão, do modelo racional ao comportamental: uma síntese teórica. Caderno de Pesquisas em Administração. São Paulo, v. 11, n. 4, 2004. p. $13-30$.

HALL, P. A.; TAYLOR, R. C. R. As três versões do neo-institucionalismo. Lua Nova: Revista de Cultura e Política, n. 58, p. 193-223, 2003.

HINICH, M. J.; MUNGER, M. C. Analytical Politics. Cambridge University Press. 1998.

KIEWIET, D. R.; MCCUBBINS, M. D. The Logic of Delegation. [s.1.]: University Of Chicago Press, 1991.

KREHBIEL, K. Information and Legislative Organization. University of Michigan Press, 1992.

LOUSADA, M.; VALENTIM, M. L. P. Modelos de tomada de decisão e sua relação com a informação orgânica. Perspectivas em Ciência da Informação Online, v.16, p.147-164, 2011.

MALTZMAN, F. Competing Principals: Comittees, Parties, and the Organization of Congress. 2001.

MAYHEW, D. R. Congress: The Electoral Connection. New Haven, Yale University Press. 1974.

MCKELVEY, R. D. Intransitivities in Multidimensional Voting Models and Some Implications for Agenda Control. Journal of Economic Theory. 12, 472-482. 1976.

MINTZBERG, H. Criando organizações eficazes: estruturas em cinco configurações. trad. Ailtom Bomfim Brandão. 2. ed. 7 reimp. São. Paulo: Atlas, 2012.

MIRANDA, R. C. R. Gestão do conhecimento estratégico na Câmara dos Deputados: uma avaliação teórico-sistêmica. In: Roberto Campos da Rocha Miranda. (Org.). Informação e Conhecimento no Legislativo. 1 ed. Brasília: Edições Câmara, 2012, v. 1, p. 141-162. 
Disponível

<http://livroaberto.ibict.br/bitstream/1/542/1/informacao_conhecimento_miranda.pdf> Acesso em: 6 dez. 2013.

MIRANDA, R. C. R. Gestão do conhecimento estratégico: uma proposta de modelo integrado. Tese (Doutorado em Ciência da Informação). Brasília: UnB, Departamento de Ciência da Informação e da Documentação, 2004.

MIRANDA, R. C. R. O uso da informação na formulação de ações estratégicas pelas empresas. Ciência da Informação [on line], Brasília, v. 28, n. 3. 1999. p. 286-292.

MOE, T. M. The New Economics of Organization. American Journal of Political Science, v. 28. n. 4. nov. 1984, 739-777.

PFEFFER, J. Evite estes Três Erros Comuns ao Tomar Decisões. Disponível em: $<\mathrm{http} / / /$ businesslifemanagement.wordpress.com/tag/as-armadilhas-escondidas-na-tomada-dedecisao/ > Acesso em: 16 abr. 2013.

POLSBY, N. W.; SCHICKLER, E. Landmarks in the Study of Congress since 1945. Annu. Rev. Polit. Sci., v. 2002, n. 5, p. 333-67, 2002.

PORTER, M. E. What is strategy? Harvard Business Review. Nov./Dec. 1996. p. 61-78.

SANTOS, F. O Poder Legislativo no Presidencialismo de Coalizão. Belo Horizonte Rio de Janeiro: UFMG, IUPERJ, 2003.

SANTOS, F.; ALMEIDA, A. Fundamentos informacionais do presidencialismo de coalizão. 1. ed. (Coleção ciências sociais). Curitiba: Appris, 2011.

SCHUMPETER, J. A. Capitalismo, socialismo e democracia. (biblioteca de ciencias sociais. economia). Rio de Janeiro: Zahar, 1984.

SELLTIZ, et. alii. Métodos de pesquisa nas relações sociais. 7.ed. Trad. Dante Moreira Leite. (Coleção Ciências do Comportamento). São Paulo: EPU, 1974.

SIMON, H. A. The new science of management decision. New York, Harper \& Row. 1960.

VARIAN, H. R. Microeconomia: uma abordagem moderna. 8. ed. Rio de Janeiro: Elsevier, 2012.

WEINGAST, B.; MARSHALL, W. The Industrial Organization of Congress; or, Why Legislatures, Like Firms Are Not Organized as Markets? Journal of Political Economy. v. 96. 1983

WILliAMS, G. A.; MILLER, R. B. Mude a forma de persuadir. HSM Management. 35 novembro-dezembro 2002.2 Disponível em: <http://lcodelima.files.wordpress.com/2011/08/a06n35n011.pdf> Acesso em: 16 abr. 2013.

Artigo recebido em: 12/12/2013

Artigo aceito para publicação em: 16/12/2013 